\title{
To breathe or to breathe better: Is that the question?
}

\author{
Vivek Rao, MD, PhD, FRCS
}

\footnotetext{
From the Division of Cardiovascular Surgery, Peter Munk Cardiac Centre, Toronto General Hospital, University of Toronto, Toronto, Ontario, Canada.

Disclosures: Dr Rao is a consultant and Member of the Medical Advisory Board of CorMatrix Cardiovascular Inc. Received for publication Aug 11, 2017; accepted for publication Aug 26, 2017; available ahead of print Oct 10 , 2017.

Address for reprints: Vivek Rao, MD, PhD, FRCS, Chief Cardiovascular Surgery, Munk Professor in Advanced Cardiac Therapeutics, 4PMB-457, 200 Elizabeth St, Toronto, Ontario M4W 3X5, Canada (E-mail: vivek.rao@ uhn.ca).

J Thorac Cardiovasc Surg 2017;154:1971-2

$0022-5223 / \$ 36.00$

Copyright (c) 2017 by The American Association for Thoracic Surgery

http://dx.doi.org/10.1016/j.jtcvs.2017.08.080
}

Durable mechanical circulatory support is now the standard of care for patients with advanced heart failure. The most recent INTERMACS (Interagency Registry for Mechanically Assisted Circulatory Support) report now suggests an overall 2-year survival in excess of $70 \%$. $^{1}$ The improved results are due largely to more stringent patient selection. In addition, there has been a definite trend toward implantation in lower INTERMACS classes (III and IV vs I and II), with an increasing trend of extracorporeal life support or shortterm paracorporeal devices for those acutely ill patients in INTERMACS class I. ${ }^{1,2}$

Several clinical risk factors have been described to predict mortality after implantation of a continuous-flow left ventricular assist device. These include severe right ventricular dysfunction, renal failure, liver cirrhosis, and malnutrition. Many of these chronically ill patients have cachexia and abnormal respiratory function. Furthermore, many patients with ischemic cardiomyopathy have a smoking history and a component of chronic obstructive pulmonary disease.

Routine preoperative pulmonary function tests (PFTs) have been used to screen patients before consideration of conventional cardiac surgery. Generally, a forced expiratory volume in 1 second $\left(\mathrm{FEV}_{1}\right)$ of less than $1 \mathrm{~L} / \mathrm{s}$ or a diffusing capacity of lung for carbon monoxide of less than $40 \%$ predicted preclude successful surgery, because these patients are at high risk for requiring prolonged ventilation, tracheostomy, and other morbidity. In patients with heart failure, these values become more difficult to interpret.

In this issue of the Journal, Bedzra and colleagues ${ }^{5}$ have examined the utility of preoperative PFTs in predicting survival after implantation of a continuous-flow left ventricular assist device. They found no correlation with survival but noted that those patients in the lowest $\mathrm{FEV}_{1}$ and diffusing capacity of lung for carbon monoxide groups had longer hospital stays. Although I agree in general with the assertion of Bedzra and colleagues ${ }^{5}$ that PFTs in isolation should not preclude consideration for implantable ventricular assist device therapy, I hesitate in making the extrapolation that PFTs should be ignored.

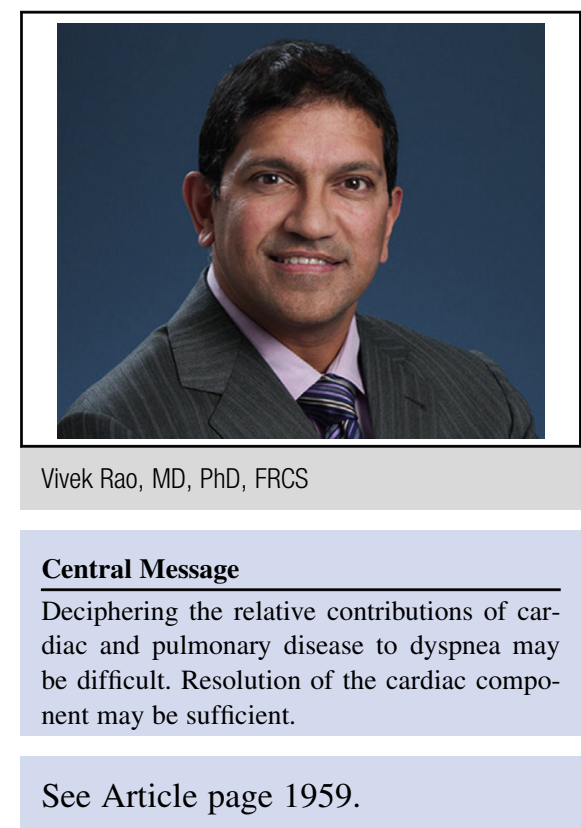

In a heart failure population, active pulmonary congestion or pleural effusions can adversely impact the results of routine spirometry. In contrast to parenchymal lung disease, spirometric analyses can improve after diuresis or drainage of the effusions. In this retrospective study, Bedzra and colleagues ${ }^{5}$ were unable to determine whether active heart failure was present at the time of PFT assessment. Furthermore, there were only a small number of patients $(n=13)$ in the lowest $\mathrm{FEV}_{1}$ group. Bedzra and colleagues ${ }^{5}$ do not indicate whether any of these patients had an absolute $\mathrm{FEV}_{1}$ of less than $1 \mathrm{~L} / \mathrm{sec}$.

I completely agree with Bedzra and colleagues ${ }^{5}$ that left ventricular assist device therapy can significantly improve pulmonary function by reducing congestion secondary to chronic heart failure. Determining which patients will have the greatest benefit may continue to be challenging. A combination of an accurate history and physical examination (looking for clinical signs of chronic obstructive pulmonary disease) and radiologic assessments with computed tomography to identify bullous or parenchymal lung disease more accurately are needed. In addition to the standard spirometric assessments described in this study, clinicians will have a more complete understanding of the relative contributions of pulmonary versus cardiac disease on a patient's dyspneic burden. As shown by the results of Bedzra and colleagues, ${ }^{5}$ it may not be necessary for the patient to breathe normally but simply to breathe better 
after resolution of the heart failure component to their dyspnea.

\section{References}

1. Kirklin JK, Naftel DC, Pagani FD, Kormos RL, Stevenson LW, Blume ED, et al. Seventh INTERMACS annual report: 15,000 patients and counting. J Heart Lung Transplant. 2015;34:1495-504.

2. Rao V. Resurgence of extracorporeal support for the primary management of cardiogenic shock. J Thorac Cardiovasc Surg. 2015;150:341-2.
3. Cowger J, Sundareswaran K, Rogers JG, Park SJ, Pagani FD, Bhat G, et al. Predicting survival in patients receiving continuous flow left ventricular assist devices: the HeartMate II risk score. J Am Coll Cardiol. 2013;61:313-21.

4. Teuteberg JJ, Ewald GA, Adamson RM, Lietz K, Miller LW, Tatooles AJ, et al. Risk assessment for continuous flow left ventricular assist devices: does the destination therapy risk score work? An analysis of over 1,000 patients. J Am Coll Cardiol. 2012;60:44-51.

5. Bedzra EKS, Dardas TF, Cheng RK, Pal JD, Mahr C, Smith JW, et al. Pulmonary function tests do not predict mortality in patients undergoing continuous-flow left ventricular assist device implantation. J Thorac Cardiovasc Surg. 2017;154:1959-70.e1. 